\title{
Implementering av en strukturerad intervju \\ (ASI) i missbruksvård och kriminalvård
}

CHRISTER ENGSTRÖM \& BENGT-ÅKE ARMELIUS

Artikeln redovisar resultatet från en nationell enkät om implementeringen av Addiction Severity Index (ASI) till 555 anställda $i$ socialtjänsten, kriminalvården och $i$ missbrukarvården som deltagit i en ASI-utbildning mellan år 1996 -2000. Resultatet visar att det är arbetsledare och chefer som alltmer tar initiativet till ASI-utbildningar och att implementeringens villkor skiljer sig åt beroende på var man arbetar. ASI har främst använts i det direkta klientarbetet och i liten utsträckning för uppföljning och utvärdering. ${ }^{1}$

Addiction Severity Index (ASI) är en strukturerad utvärderings- och klientbedömningsmetod som fått stor spridning såväl i Sverige som internationellt (Leonhard et al. 2000, Andrén et al. 2001). ASI skapades redan 1980 för att utvärdera behandlingsprogram för alkohol- och drogproblem

Bengt-Åke Armelius är professor vid institutionen för psykologi, Umeå universitet.

Christer Engström är doktorand vid institutionen för psykologi, Umeå universitet
(McLellan et al. 1980) och har reviderats fem gånger varav senast 1992 (McLellan et al. 1992). Det finns ett flertal studier som visar att ASI som forskningsinstrument har god reliabilitet och validitet men det förutsätts utbildning och övning för att kunna genomföra en intervju med bra kvalitet

1 Denna studie genomfördes med stöd av Centrum för utvärdering av socialt arbete (CUS) och i samarbete med Siv Nyström på CUS. 
(Grissom \& Bragg 1991, Wertz et al. 1995). ASI är översatt till många olika språk och sedan 1996 finns en svensk version (Andréasson et al. 1996). ASI består av ett formulär för mer omfattande dokumentation och ett kortare formulär för uppföljning. Intervjun innehåller förutom frågor om alkohol och droger även områden som fysisk hälsa, arbete/försörjning, kriminalitet, familj/ umgänge och psykiska hälsa.

I Sverige startade ASI-utbildningar i liten skala 1996 och har sedan dess ökat i omfattning. Från och med år 2000 finns det en nationell standard i Sverige som omfattar tre dagars utbildning som ger behörighet att använda ASI-intervjun. Eftersom ASI-intervjun är väl utprövad kan den bli ett värdefullt hjälpmedel vid utredningar, behandlingsplanering och vid mer systematiska uppföljningar och utvärderingar av insatser för alkohol- och drogmissbrukare. Användningen av utprövade metoder är en viktig del i en evidensbaserad missbrukarvård. Implementering av ASI-intervjun kan i vidare bemärkelse bli modell för implementering av metoder med vetenskapligt stöd i socialtjänsten (SoS 2001, SBU 2001). I Sverige har fram till år 2000 uppskattningsvis cirka 1000 socialarbetare, behandlingspersonal och kriminalvårdspersonal deltagit $\mathrm{i}$ någon utbildning på ASI-intervjun. Men det har inte gjorts någon undersökning om och i vilken omfattning ASI-intervjun fortsättningsvis har använts av dem som deltagit $\mathrm{i}$ dessa utbildningar.

\section{Policybeslut och implementering}

En Policy brukar definieras som ett beslut om en handlingslinje eller en målbeskrivning för en verksamhet. Exempel på policybeslut är socialstyrelsens program för en kunskapsbaserad socialtjänst (SoS 2001). Implementering är den process som genomför sådana policybeslut i praktiken (Sannerstedt 2001). Incitamentet till implementeringsforskningen var erfarenheten att många beslut förändrades under genomförandet eller att beslutet inte ens genomfördes i praktiken (Björkemarken 1995). Implementeringsforskningen har utkristalliserat två skilda perspektiv. "Top-down" perspektivet fokuserar på hur beslut som tagits i organisationens topp förs vidare ner genom organisationen mot genomförande. "Bottom-up" perspektivet handlar om hur de som arbetar i verksamheten själva tar initiativ för att utveckla sina arbetsuppgifter. Uppifrånperspektivet handlar om "beslutsfattarnas avsikter" medan nerifrånperspektivet handlar om "tillämparnas handlande» (Sannestedt 2001 s. 23). Ett exempel på en teori som utgår från ett nerifrånperspektiv är Lipskys (1980) teori om "närbyråkrater». Som närbyråkrater räknas lärare, sjukvårdspersonal och socialarbetare. Gemensamt för dessa yrkesgrupper är att de arbetar med människor och att det är klientens behov, professionella normer och sakkunskaper som avgör hur arbetet skall bedrivas. Lipsky menar att dessa grupper har så stor handlingsfrihet att de i vissa avseenden är oberoende av beslut på högre nivåer.

Policyprocessen liksom implementeringsprocessen är ofta en sammanhängande kedja av beslut med många beslutsfattare inblandade. Friedman (2003) har beskrivit policy och implementeringsprocessen i fem 
steg. Första steget är att identifiera vilket problem som man avser att lösa (identifikation). Andra steget är att fatta ett beslut om åtgärder för att lösa problemet (policyutveckling). Tredje steget är genomförandet av beslutet (implementering). Fjärde steget är att utvärdera resultatet (utvärdering) och slutligen femte steget som innebär att förändra beslutet (modifiera) på basis av den information som utvärderingen gav. Det nya modifierade beslutet implementeras sedan i den pågående processen. Fördelen med Friedmans modell är att besluts- och implementeringsprocessen tillåts påverka varandra. Lundqvist (1987) har formulerat tre villkor som bör gälla för att genomföra ett policybeslut. Första villkoret är att det går att förstå beslutet och det andra är att man kan och har tillräckligt med resurser för att genomföra beslutet. Det tredje villkoret är att man faktiskt vill genomföra beslutet.

\section{Modell för implementering av ASI-intervjun}

Målet med implementering av nya metoder och arbetssätt är i de flesta fall att de skall underlätta eller förbättra verksamhetens arbete. Innan sådana projekt startar bör det klart framgå varför metoden bör användas, hur den skall användas och vad som är målet med användningen. Vid senare utvärdering av implementeringen kan sedan resultatet jämföras med sådana beskrivningar. Syftet med ASI-intervjun är att den skall användas för att ge en dokumentation av klientens livssituation innan någon insats görs dels för att underlätta för val av behandling och dels som bas- linje inför senare uppföljningar och utvärderingar. Baslinjen skall sedan jämföras med ASI-uppföljningsintervjun som görs efter en viss tid för att visa på eventuella förändringar i klientens livssituation mellan dessa två tidpunkter. En systematisk användning av intervjun innan någon behandling påbörjas och som uppföljning vid senare bestämda tidpunkter för alla klienter är en förutsättning för senare sammanställning av data på gruppnivå. I figur 1 nedan beskriver vi en modell för implementeringen av ASI-intervjun uppdelad på fyra specifika faser eller delmål. Första fasen är att utforma ett beslut och en plan för hur ASI-intervjun skall användas samt att utbilda de som skall använda intervjun. Den andra fasen är att använda ASIintervjun i klientarbetet och den tredje fasen är att använda den för uppföljning efter behandlingen eller andra insatser för enskilda klienter. I fjärde fasen är målet att sammanställa data på gruppnivå och att utnyttja informationen för ett organisatoriskt lärande. Systematisk användning i Fas 2 och i Fas 3 är en förutsättning för senare sammanställning av data på gruppnivå.

\section{Figur I.}

En modell för implementering av ASI-intervjun uppdelad påfyra faser.

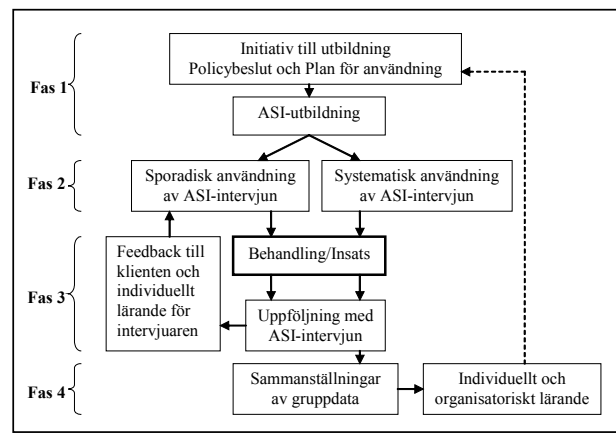




\section{Implementering av strukturerade dokumentationsmetoder}

Ett av de första försöken att implementera strukturerade dokumentationsmetoder i den svenska missbrukarvården genomfördes vid mitten av 1980-talet i BAK/SWEDATE projektet (Bergmark \& Oskarsson 1996). Syftet var bland annat att utveckla metoder för systematisk dokumentation och att stimulera intresset för egenutvärdering men resultatet blev att endast ett par enheter fortsatte att använda metoderna efter att projektet avslutats. En anledning var att den cirka en timme långa intervjun upplevdes som alltför tidskrävande när det inte fanns särskild personal avsatt för att göra en sådan dokumentation.

En annan dokumentations- och utvärderingsmetod som implementerats i missbrukarvården är DOK-systemet (Jenner \& Segraeus 1996). En pilotstudie som genomfördes 1994 visade att det fanns en positiv inställning till DOK-systemet men också att deltagarna inte använde formulären systematiskt. Ahlberg och Leissner (1996) som utvärderade implementeringen konstaterar i ett senare skede av projektet att DOK verkar fungera bäst $\mathrm{i}$ traditionella vårdkulturer med tidigare erfarenheter av strukturerade dokumentationssystem. Man konstaterar vidare att det finns en risk att DOK-systemet kan medföra en hårdare styrning av och en ökad insyn i det "privata" behandlingsarbetet. DOK-systemet har främst implementerats i den specialiserade missbrukarvården och i mindre omfattning på socialkontor inom socialtjänsten.
"Tidig Intervention" är en metod som prövats i den svenska primärvården (Andréasson et al. 2000). Metoden syftar till att upptäcka alkoholproblem på ett tidigt stadium. Trots att det finns vetenskapligt stöd för värdet av metoden misslyckades försöket att implementera metoden i primärvården. Läkarna och sjuksköterskorna som deltog i studien var inte intresserade av att använda metoden om det inte redan var uppenbart att patienten hade alkoholproblem. En annan anledning till att implementeringen misslyckades var att deltagarna fick för lite stöd under implementeringsfasen vilket tidigare forskning visat vara av stor betydelse för resultatet (Gomel et al. 1998).

I England har ett strukturerat bedömnings- och insatsformulär utvecklats för utredning och uppföljning av barns behov (Department of Health 1999). Den engelska versionen heter "Looking after children" (LACS) och har i svensk översättning fått namnet "Barns behov i centrum" (BBiC) (SoS-rapport 2002). I Sverige pågår försök att implementera $\mathrm{BBiC}$ i sju kommuner. LACS har i England kritiserats för att föra in positivistiska inslag i det sociala arbetet (Webb 2001). Kritikerna menar att den typen av forskningsbaserade instrument företräder en kunskapssyn som är främmande för socialarbetarkulturen (Garett 2002).

Holland (1999) har i en studie visat att socialarbetare som arbetar med utredning och omhändertagande av barn pendlar mellan ett "objektivt» vetenskapligt förhållningssätt och ett "subjektivt" stödjande och hjälpande förhållningssätt under mötet med klienten. Lesche (1971) 
har beskrivit hur psykoterapeuter växlar mellan ett "hermeneutiskt" och ett "kvasinaturalistiskt» förhållningssätt under ett samtal med klienten. I den hermeneutiska fasen förstår terapeuten vad klienten försöker förmedla och kan även förmedla klienten denna förståelse för att öka hans självkännedom. Förr eller senare kommer emellertid samtalet in en fas där terapeuten inte längre förstår vad klienten försöker förmedla. För att komma vidare i sin förståelse lämnar då terapeuten temporärt den hermeneutiska positionen till förmån för en "kvasinaturalistisk" position. I den positionen dominerar teoretiska förklaringar och klienten blir ett objekt för behandlaren. Med hjälp av teorier skapar terapeuten nya hypoteser om klienten som bidrar till att dialogen kan återupptas. Terapeutens växling mellan dessa två positioner kan användas som en modell för socialarbetarens arbete med utredningar, behandlingsplanering och behandling. Under en utredning är det nödvändigt att använda såväl teorier som empirisk information som erhållits genom strukturerade intervjuer, mätningar eller skattningar, för att öka sin förståelse för klientens livssituation.

\section{Syfte}

Syftet med denna studie är att undersöka implementeringen av ASI-intervjun för alla som deltagit i ASI-utbildning i Sverige. Undersökningen fokuserar på följande områden a) ASI-utbildningen, b) hur ASIintervjun används och c) vad som skulle underlätta den fortsatta användningen samt d) antal genomförda ASI-intervjuer.
Resultatet från denna studie kan användas som feedback till den pågående implementeringen av ASI-intervjun och bidra med erfarenheter till andra som står i begrepp att inleda en sådan implementering. Resultatet kan också få betydelse för implementering av andra behandlingsmetoder i missbrukarvården som har vetenskapligt stöd (se SBU-2001).

\section{Metod}

Studien som genomfördes hösten 2000 var baserad på en enkät till 555 personer som deltagit i ASI-utbildning från det att utbildningarna började 1996 till och med första halvåret år 2000. Det saknas deltagarlistor från en del utbildningar som genomfördes mellan 1996-1998 men i stort sett samtliga som deltagit i utbildning under 1999 och under första halvåret år 2000 ingår i denna studie. Den statistiska analysen har gjorts iSPSS.

\section{Resultat}

Svarsfrekvensen blev 65 procent $(\mathrm{n}=362)$ och deltagarna hade en medelålder på 46 år varav 70 procent var kvinnor. Hälften av dem som svarade på enkäten arbetade $i$ socialtjänsten och en fjärdedel i kriminalvården. Återstående fjärdedelen arbetade huvudsakligen i behandlingsverksamheter som drivs privat eller i sjukvårdens regi. Data kommer fortsättningsvis att grupperas under (S) för socialtjänst, $(K)$ för kriminalvård och (B) för de som arbetar med behandling. I tabell 1 redovisas svarsfrekvens och bortfall för S, K och B-grupperna. 


\section{Tabell I.}

Svarsfrekvens och bortfall för respondenter som arbetar inom socialtjänst (S), kriminalvård (K) och behandlingsgrupp (B)

\begin{tabular}{|lcccccccc|}
\hline & \multicolumn{2}{c}{ S-gruppen } & \multicolumn{2}{c|}{ K-gruppen } & \multicolumn{2}{c|}{ B-gruppen } & \multicolumn{2}{c|}{ Totalt } \\
& $\mathrm{n}$ & $\%$ & $\mathrm{n}$ & $\%$ & $\mathrm{n}$ & $\%$ & $\mathrm{n}$ & $\%$ \\
\cline { 2 - 9 } Svarsfrekvens & 182 & 58 & 81 & 77 & 99 & 73 & 362 & 65 \\
Bortfall & 132 & 42 & 24 & 23 & 37 & 27 & 193 & 35 \\
\cline { 2 - 10 } Totalt & 314 & 100 & 105 & 100 & 136 & 100 & 555 & 100 \\
\hline
\end{tabular}

Resultatet visar att S-gruppen bidrar med hälften av de svarande men att de också har det största egna bortfallet (42 \%). K gruppen som är något mindre än $\mathrm{B}$ gruppen har också det minsta bortfallet (23\%). En vidare analys av data visar att kvinnornas andel av dem som svarade var 74 procent i S-gruppen, 62 procent i K och 69 procent i B-gruppen. Kvinnornas andel av bortfallet var 67 procent i S-gruppen, 62 procent i K och 65 procent i B-gruppen. Vår slutsats är att bortfallet med avseende på kön inte är snedfördelat mellan grupperna. Bortfallets fördelning med avseende på ålder går inte att beräkna eftersom vi saknar uppgifter om ålder för de som inte svarade på enkäten. Däremot är bortfallet mycket högre i S-gruppen jämfört med de två andra grupperna.

\section{ASI-utbildningen och den fort- satta användningen avintervjun}

I tabell 2 redovisas vem som tog initiativet till utbildningen, omdömet om utbildningen, vilket år utbildningen genomfördes, om de genomfört någon ASI-intervju efter utbildningen och anledningen till att de inte genomfört någon intervju.

\section{Tabell 2.}

Initiativet till utbildningen, omdömet om utbildningen och de år de deltog i en ASI-utbildning samt den fortsatta användningen av ASI-intervjun.

\begin{tabular}{|c|c|c|c|c|c|c|c|c|c|}
\hline \multirow[b]{2}{*}{ Fråga } & \multirow[b]{2}{*}{ Svarsalternativ } & \multicolumn{2}{|c|}{$\mathbf{S}$} & \multicolumn{2}{|c|}{$\mathbf{K}$} & \multicolumn{2}{|c|}{ B } & \multicolumn{2}{|c|}{ Totalt } \\
\hline & & $\mathrm{N}$ & $\%$ & $\mathrm{~N}$ & $\%$ & $\mathrm{~N}$ & $\%$ & $\mathrm{~N}$ & $\%$ \\
\hline \multirow{2}{*}{$\begin{array}{l}\text { Vem tog initiativ till din ASI- } \\
\text { utbildning }\end{array}$} & Chefer & 110 & 61 & 49 & 66 & 47 & 49 & 206 & 59 \\
\hline & Eget/arbetskamrat & 55 & 31 & 9 & 12 & 41 & 42 & 105 & 30 \\
\hline \multirow{2}{*}{$\begin{array}{l}\text { Vilket omdöme ger du ASI- } \\
\text { utbildningen }\end{array}$} & Mycket Bra & 36 & 21 & 15 & 20 & 31 & 34 & 82 & 24 \\
\hline & Ganska bra & 137 & 78 & 49 & 65 & 57 & 62 & 243 & 71 \\
\hline $\begin{array}{l}\text { Vilket år deltog du i ASI- } \\
\text { utbildning? }\end{array}$ & 1999-2000 & 110 & 62 & 67 & 88 & 67 & 71 & 244 & 70 \\
\hline \multirow{2}{*}{$\begin{array}{l}\text { Har du genomfört någon ASI- } \\
\text { intervju efter din ASI-utbildning }\end{array}$} & $\mathrm{Ja}$ & 109 & 61 & 55 & 70 & 54 & 55 & 218 & 61 \\
\hline & $\mathrm{Nej}$ & 71 & 39 & 24 & 30 & 44 & 45 & 139 & 39 \\
\hline Varför har du inte gjort någon & ASI passar ej & 12 & 18 & 6 & 24 & 10 & 21 & 28 & 19 \\
\hline ASI-intervju efter utbildningen? & Inga möjligheter & 13 & 19 & 5 & 20 & 12 & 22 & 30 & 21 \\
\hline
\end{tabular}

*1 Chi-Square, $(4, N=350)=22.84, p=.000$

*2 Chi-Square, $(4, N=342)=26,03, p=.000$

*3 Chi-Square, $(4, N=346)=26,03, p=, 014$ 
Det finns signifikanta skillnader mellan S-, K- och B-grupperna med avseende på vem som tog initiativ till utbildningen, vilket omdöme utbildningen får och vilket år de deltog i utbildningen. Chefer och arbetsledare var den vanligaste initiativtagaren till ASI-utbildningen i alla tre grupperna. Skillnaden mellan grupperna är att K-gruppen har hög andel på initiativ av "chefer" (66 \%) medan B-gruppen har låg andel (49 \%). B-gruppen har hög andel »eget/arbetskamraters» initiativ (42\%) och K-gruppen låg andel (12\%) och K-gruppen har hög andel på initiativ från "andra" (22 $\%)$ medan S-gruppen har låg andel (8 \%). Mönstret är alltså att ASI-utbildningen i S och B-gruppen i högre utsträckning är ett initiativ "nerifrån" jämfört med K-gruppen som mer har ett "uppifrån" eller "utifrån» initiativ. När det gällde omdömet om utbildningen är skillnaden att B-gruppen är högst på alternativet »mycket bra» (34 \%) och K-gruppen lägst (20\%). S-gruppen har jämförelsevis det högsta värdet på alternativet "ganska bra" (78 \%) medan K-gruppen är högst på alternativet »inte så bra» (15\%). Mönstret är att B-gruppen är mest nöjd och K-gruppen minst nöjd med utbildningen. Skillnaden mellan det år man gick utbildningen är att S-gruppen har en stor andel deltagare i utbildningar före 1999 (38 \%) och K-gruppen liten andel (12\%). Vidare bearbetning av data visar att andelen eget/ arbetskamraters initiativ i socialtjänsten är högst 1997 för att sedan successivt minska fram till år 2000. Om den trenden består kommer skillnaden i det avseendet mellan socialtjänsten och kriminalvården att försvinna. Ett intressant fynd är att 41 procent av alla som huvudsakligen arbetar med behandling svarade att ASI-intervjun inte passar för deras arbete medan motsvarande värde för de som huvudsakligen arbetar med utredning bara var 8 procent. Resultatet tyder på att ASI-intervjun passar bättre i utredningsorienterade arbetsuppgifter och mindre bra för behandlingsorienterade arbetsuppgifter (Kullberg 2002).

\section{De som har använt intervjun efter utbildningen}

Av de 362 personer som svarade på enkäten har 60 procent $(n=218)$ använt ASIintervjun i sitt arbete efter utbildningen. I tabell 3 redovisas behovet av stöd för dem som började använda intervjun efter utbildningen, om de fick sådant stöd, möjligheter att använda ASI-intervjun på sin arbetsplats och hur stor andel klienter som intervjuas.

Resultatet visar att det finns en signifikant skillnad mellan S-, K- och B-grupperna med avseende på behov av stöd, det stöd de fick och möjligheterna att använda ASI-intervjun på arbetsplatsen. Skillnaden mellan grupperna är att K-gruppen behöver mest stöd efter utbildningen (60 $\%$ ) och B-gruppen behöver minst stöd (33 $\%)$. S-gruppen fick mest stöd (60 \%) och K-gruppen fick minst stöd (22 \%). K-gruppen hade den högsta andelen som skattade att de hade dåliga möjligheter att använda ASI på sin arbetsplats (33 \%) och S-gruppen den lägsta andelen (7\%). Mönstret är att det är K-gruppen som har mest behov av stöd och de sämsta möjligheterna att använda ASI-intervjun samtidigt som de fick sådant stöd i mindre utsträckning än de två andra grupperna. Anledningen kan vara att krimi- 


\section{Tabell 3.}

Deltagarnas behov av stöd och det stöd de fick, möjligheterna att använda ASI-intervjun i sitt arbete samt hur stor andel av klienterna som intervjuas med ASI-intervjun för de som använt intervjun $i$ sitt arbete efter utbildningen.

\begin{tabular}{|c|c|c|c|c|c|c|c|c|c|}
\hline \multirow[b]{2}{*}{ Fråga } & \multirow[b]{2}{*}{ Svarsalternativ } & \multicolumn{2}{|c|}{$\mathbf{S}$} & \multicolumn{2}{|c|}{$\mathbf{K}$} & \multicolumn{2}{|c|}{ B } & \multicolumn{2}{|c|}{ Totalt } \\
\hline & & $\mathrm{N}$ & $\%$ & $\mathrm{~N}$ & $\%$ & $\mathrm{~N}$ & $\%$ & $\mathrm{~N}$ & $\%$ \\
\hline Behövde du stöd av något & $\sqrt{\mathrm{Ja}}$ & 42 & 38 & 32 & 60 & 18 & 33 & 92 & 42 \\
\hline slag den första tiden då du & Nej & 40 & 36 & 4 & 8 & 25 & 46 & 69 & 32 \\
\hline Fick du det stöd du behövde & $\mathrm{Ja}$ & 61 & 60 & 11 & 22 & 27 & 54 & 99 & 49 \\
\hline den första tiden du använde & Delvis & 24 & 24 & 18 & 37 & 16 & 32 & 58 & 29 \\
\hline använda ASI på din arbets- & Dåliga & 8 & 7 & 17 & 33 & 10 & 18 & 35 & 17 \\
\hline plats & Vet ej & 7 & 7 & 2 & 4 & 3 & 6 & 12 & 6 \\
\hline Hur stor andel av klienter & $81-100 \%$ & 39 & 43 & 17 & 42 & 24 & 52 & 80 & 45 \\
\hline med missbruksproblem & $21-80 \%$ & 17 & 19 & 5 & 13 & 4 & 9 & 26 & 15 \\
\hline intervjuar du med ASI & $0-20 \%$ & 35 & 38 & 18 & 45 & 18 & 40 & 71 & 40 \\
\hline
\end{tabular}

*1 Chi-Square, $(4, N=217)=21.07, p=, 000$

*2 Chi-Square, $(4, N=200)=23,31, p=, 000$

*3 Chi-Square, $(4, N=210)=16,58, p=, 002$

nalvården började implementera intervjun senare och att skillnaden mellan grupperna avspeglar att grupperna är i olika faser.

\section{Hur har ASI intervjun använts?}

ASI-intervjun har flera olika användningsområden som utredning, klientbedömningsmetod, för behandlingsplanering, verksamhetsplanering och forskning. I tabell 4 redovisas hur ASI-intervjun har använts och vad som skulle underlätta den fortsatta användningen av intervjun. Under rubriken alternativ finns de svarsalternativ som användarna kunde välja mellan och i tabellen redovisas frekvensen för dem som svarat ja på respektive alternativ. Ett eller flera alternativ kunde väljas.

ASI-intervjun har främst använts som basinformation i utredningar (63\%) och som bedömningsunderlag (62\%). Allra minst har den använts för enhetsplane- ring (11\%). Mönstret är att intervjun har använts som ett hjälpmedel i klientarbetet och i mycket liten utsträckning för utvärdering. En fjärdedel av användarna ville ha hjälp med att utnyttja den information som intervjun ger. Anledningen är troligen att intervjun ger så mycket information att det är svårt, för att inte säga omöjligt, att hantera den ansenliga mängd information som en ASI-intervju ger utan datastöd. När denna studie gjordes hade användarna inte tillgång till något dataprogram för att bearbeta och sammanställa data.

Det finns signifikanta skillnader mellan grupperna med avseende på användning av ASI-intervjun som basinformation i utredning, diskussion i klientarbetet, beslut om behandling, användning för forskning och utvärdering samt att det skulle underlätta den fortsatta användningen om man fick mer tid och mer stöd av chefen. S-gruppen har använt ASI-intervjun jämförelsevis mest som basinformation vid utredning ( 74 


\section{Tabell 4.}

Hur deltagarna har använt ASI-intervjun och vad som skulle underlätta en fortsatt användning av ASI-intervjun.

\begin{tabular}{|c|c|c|c|c|c|c|c|c|c|c|}
\hline \multirow[b]{2}{*}{ Fråga } & \multirow[b]{2}{*}{ Svarsalternativ } & \multirow[b]{2}{*}{ Svar } & \multicolumn{2}{|c|}{ S-gruppen } & \multicolumn{2}{|c|}{ K-gruppen } & \multicolumn{2}{|c|}{ B-gruppen } & \multicolumn{2}{|c|}{ Totalt } \\
\hline & & & $\mathrm{N}$ & $\%$ & $\mathrm{~N}$ & $\%$ & $\mathrm{~N}$ & $\%$ & $\mathrm{~N}$ & $\%$ \\
\hline \multirow{7}{*}{$\begin{array}{l}\text { Hur använder du } \\
\text { den information } \\
\text { som ASI-intervjun } \\
\text { ger }\end{array}$} & Basinformation i utredning & $\mathrm{Ja}$ & 81 & 74 & 29 & 57 & 26 & 48 & 136 & 63 \\
\hline & Som bedömningsunderlag & $\mathrm{Ja}$ & 67 & 61 & 28 & 55 & 38 & 70 & 133 & 62 \\
\hline & Diskussion i klientarbetet & $\mathrm{Ja}$ & 67 & 61 & 25 & 49 & 21 & 39 & 113 & 53 \\
\hline & \begin{tabular}{|l|} 
Beslut om behandling \\
\end{tabular} & $\mathrm{Ja}$ & 63 & 57 & 29 & 57 & 20 & 37 & 112 & 53 \\
\hline & Studera klientförändringar & $\mathrm{Ja}$ & 35 & 32 & 11 & 22 & 18 & 33 & 64 & 30 \\
\hline & För forskning/utvärdering & $\mathrm{Ja}$ & 12 & 11 & 4 & 8 & 21 & 39 & 37 & 17 \\
\hline & För enhetsplanering & $\mathrm{Ja}$ & 9 & 8 & 9 & 18 & 5 & 9 & 23 & 11 \\
\hline \multirow{7}{*}{$\begin{array}{l}\text { Skulle det under- } \\
\text { lätta för dig att } \\
\text { göra ASI-inter- } \\
\text { vjuer om följande } \\
\text { förbättrades }\end{array}$} & Mer tid & Ja & 32 & 37 & 43 & 83 & 19 & 46 & 94 & 52 \\
\hline & Mer kunskaper om ASI & $\mathrm{Ja}$ & 24 & 28 & 20 & 38 & 11 & 27 & 55 & 31 \\
\hline & Kunde använda data bättre & $\mathrm{Ja}$ & 19 & 22 & 17 & 33 & 9 & 22 & 45 & 25 \\
\hline & Bättre organisation & $\mathrm{Ja}$ & 13 & 15 & 12 & 23 & 7 & 17 & 32 & 18 \\
\hline & Mer Intresserade kollegor & $\mathrm{Ja}$ & 15 & 17 & 6 & 12 & 3 & 7 & 24 & 13 \\
\hline & Mer stöd av chefen & $\mathrm{Ja}$ & 3 & 3 & 16 & 31 & 4 & 10 & 23 & 13 \\
\hline & Bättre teknisk utrustning & $\mathrm{Ja}$ & 11 & 13 & 7 & 14 & 4 & 10 & 22 & 12 \\
\hline
\end{tabular}

*1 Chi-Square, $(2, \mathrm{~N}=215)=11,30, \mathrm{p}=.004$

*2 Chi-Square, $(2, N=215)=7,38, p=.025$

*3 Chi-Square, $(2, N=215)=6,55, p=.038$
*4 Chi-Square, $(2, \mathrm{~N}=215)=24,02, \mathrm{p}=.000$

*5 Chi-Square, $(2, N=179)=27,70, p=.000$

${ }^{*} 6$ Chi-Square, $(2, N=179)=21,99, p=.000$
$\%$ ) och B-gruppen minst (48 \%). S-gruppen har också använt ASI-intervjun jämförelsevis mest för diskussion i klientarbetet (61 $\%$ ) och B-gruppen minst (39 \%). S och Kgruppen har använt ASI-intervjun mer för beslut om behandling (57 \%) jämfört med B-gruppen (37 \%). Däremot har B-gruppen använt ASI-intervjun mest för forskning och utvärdering (39 \%) jämfört med de två andra grupperna. På frågan om vad som skulle underlätta den fortsatta användningen av ASI-intervjun var alla tre grupperna överens om att mer tid var den viktigaste faktorn, följt av mer kunskaper om ASI och som tredje prioritet att de skulle kunna använda data från ASI-intervjun på ett bättre sätt. Skillnaden mellan grupperna är att K-gruppen har jämförelsevis mer behov av tid (83\%) och stöd av chefen (31 \%) och S-gruppen minst (37 \% respektive $3 \%$ ).

\section{Omfattningen av ASI- användningen}

En indikator på hur implementeringen lyckas är hur många ASI-intervjuer som har genomförts efter utbildningen i de olika verksamheterna. Medelvärdet för antal intervjuer är 9 intervjuer och medianvärdet 5. I Diagram 1 redovisar vi medianvärdet för genomförda ASI-intervjuer och det år man deltog i utbildningen. Vi har använt medianvärdet som ett mått på antal genomförda ASI-intervjuer eftersom det varje utbildningsår finns några få personer som har gjort ett stort antal intervjuer medan majoriteten gjort relativt få intervjuer. Exempelvis så har en person som utbildades 1997 gjort 200 intervjuer.

Resultatet visar föga överraskande att de som deltagit i ASI-utbildningar 1997 eller tidigare har det högsta och de som utbilda- 


\section{Diagram I.}

Medianvärdet för antal genomförda ASI-intervjuer och det år man deltog i ASI -utbildning.

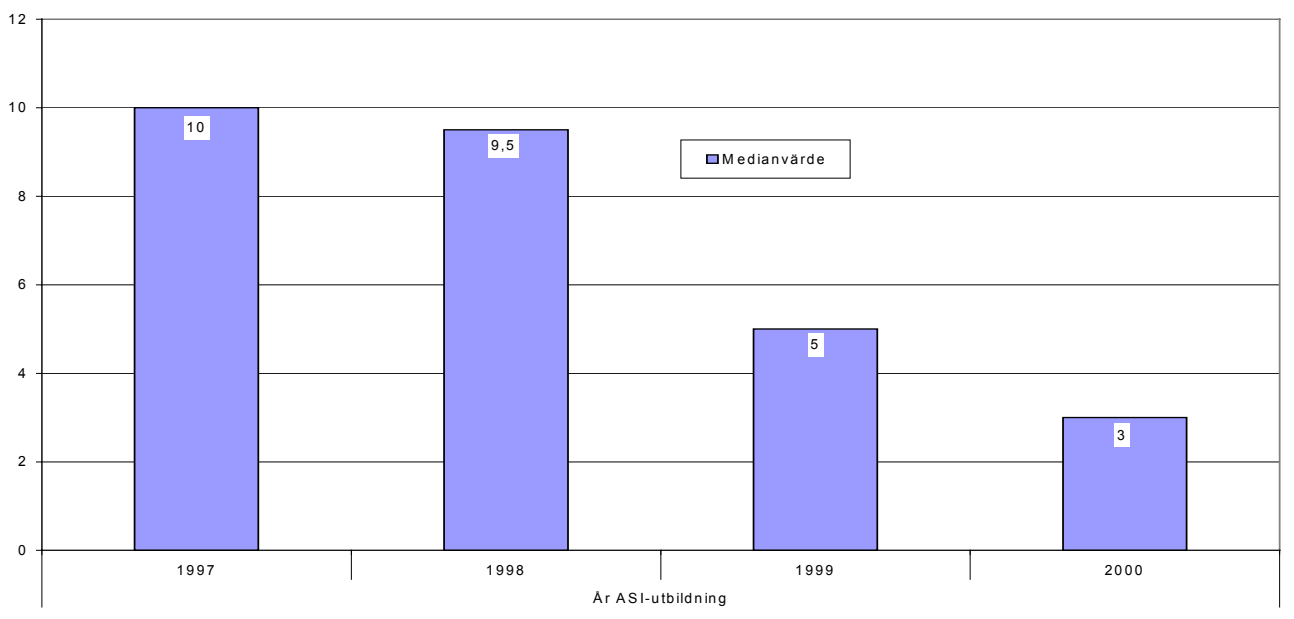

des år 2000 det lägsta medianvärdet. Resultatet visar emellertid att skillnaden med avseende på antalet intervjuer mellan 1997 och 1998 är liten. En vidare analys av data visar också att det inte finns någon skillnad mellan S-, K- eller B-grupperna med avseende på antal genomförda ASI-intervjuer efter utbildningen vilket är något förvånande. Som vi tidigare redovisat så utbildades 38 procent (se tabell 2) i S-gruppen och endast 12 procent i K-gruppen före 1999. S-gruppen borde rimligtvis ha haft fler tillfällen att göra ASI-intervjuer än K-gruppen. Antalet genomförda ASI-intervjuer för de som utbildades 1999 och år 2000 är svårare att värdera då de har förhållandevis kort tid på sig för att använda ASI-intervjun. Totalt så har deltagarna i denna studie genomfört 1777 ASI-intervjuer och 265 uppföljningsintervjuer. Av de 218 som har använt intervjun efter utbildningen har 62 personer gjort uppföljningar med ASI-intervjun varav 10 personer står för 52 procent av antalet intervjuer.

\section{Diskussion}

Syftet med denna studie var att undersöka användningen av ASI-intervjun för dem som utbildats på intervjun fram till och med första halvåret år 2000. ASI-intervjun är dock bara ett verktyg som måste relateras till vad som var syftet med användningen av intervjun. Redovisningen av resultaten från denna studie kommer därför att följa modellen för implementering av ASI-intervjun som beskrivits i figur 1 och som utgår från att ASI-intervjun rätt använd är ett mätinstrument som kan förse socialarbetaren och verksamheten med värdefull information.

\section{Fas 1. Utbildningen och Policybeslut}

Resultatet från vår studie visar att implementeringen alltmer blir ett "top down" projekt (Björkemarken 1995, Sannerstedt 2002) eftersom chefer och arbetsledare i ökad 
utsträckning tagit initiativ till utbildningarna. Allra tydligast är den trenden i socialtjänstgruppen där andelen ökat från 55 procent år 1997 till 71 procent år 2000. Skälen till chefers ökande engagemang kan vara att de har påverkats av de kvalitetskrav som sedan 1998 finns inskrivna i socialtjänstlagen. Kvalitetsutveckling, uppföljning och utvärdering har också blivit positivt värdeladdade ord även för chefer i den offentliga sektorn (Bergström 2002) samtidig som ASIintervjun blivit mer känd under senare år.

Resultatet visar att mellan 1-4 procent av deltagarna från socialtjänsten och behandlingsgruppen samt 15 procent av deltagarna från kriminalvården ansåg att utbildningen inte var så bra. Skillnaden mellan grupperna är något förvånande eftersom alla i princip fått samma utbildning och att utbildarna i många fall varit samma personer $\mathrm{i}$ alla tre grupperna.

Cirka 40 procent av deltagarna i denna studie har inte använt intervjun i sitt arbete efter utbildningen. Av dessa uppger 18-24 procent att det berodde på att intervjun inte passade för deras klienter eller för deras arbetssätt, varav drygt en tredjedel på grund av att det inte funnits något tillfälle eller saknats möjligheter att använda intervjun. Cirka 7 procent av de som deltog i utbildningarna var chefer eller arbetsledare som inte hade för avsikt att själva göra intervjuer. Utbildningen kan ändå ha ett värde eftersom den ger en behörighet att tolka och använda information från ASI-intervjuer som andra genomfört. En anledning till att 40 procent av deltagarna i denna studie inte har använt ASI-intervjun efter utbildningen kan vara att man utbildat hela arbetsgruppen och att det är först efter utbildningen som man har blivit på det klara med vilka som fortsättningsvis skall använda intervjun. Den som genomför intervjun bör vara den som har den största nyttan av informationen samtidigt som den bör göras i så nära anslutning som möjligt till den första kontakten med klienten. Verksamheten måste här göra ett strategiskt val eftersom den första intervjun med klienten bara bör göras endast en gång för att inte belasta klienten med samma frågor flera gånger. Uppföljningsintervjun kan däremot användas upprepade gånger.

\section{Fas 2. I vilken omfattning har ASI-intervjun använts?}

Resultaten från denna studie visar att 60 procent av deltagarna har använt intervjun i sitt arbete efter utbildningen. Den vanligaste användningen är som hjälpmedel i en utredning eller som bedömningsunderlag men i mycket liten utsträckning för uppföljning eller utvärdering. Det faktum att ASI-intervjun har använts i klientarbetet är en positiv faktor för den fortsatta implementeringen av ASI-intervjun. Motivationen att använda ASI-intervjun bör bli större om användarna har en omedelbar nytta av ASI-intervjun, framförallt i socialtjänsten där man tidigare varit skeptisk till att följa upp och utvärdera sina insatser (Ahlberg \& Leissner 1997, Engström \& Armelius 2002).

Resultaten visar vidare att 41 procent av kriminalvårdens deltagare upplever att de inte fått tillräckligt med stöd i denna fas. Tidigare forskning visar att det är nödvändigt med ett bra stöd till användarna för att implementeringen skall lyckas (Gomel et al. 1998, Andréasson et al. 2000). I vår 
studie ser vi emellertid ingen skillnad i antalet genomförda ASI-intervjuer mellan de som fick tillräckligt stöd och de som inte fick tillräckligt stöd. Frekvensen av ASI-intervjun tycks inte heller påverkas av att det finns olika möjligheter att använda intervjun inom skilda verksamheter. Kriminalvårdens personal har mindre stöd för att använda ASI-intervjun men har ändå använt den i samma omfattning som socialtjänsten och de som arbetar med behandling. Resultatet tyder på att det finns andra faktorer och inte bara tillgången till stöd och möjligheterna att använda intervjun som påverkar användningen.

Antalet genomförda intervjuer per deltagare är relativt litet framförallt för socialtjänstens personal som fick utbildning 1997 och år 1998. Trots att de haft möjlighet att använda intervjun under flera års tid är det få som har gjort fler än tio intervjuer. Av resultaten att döma så verkar det inträffa en mättnad kring tio intervjuer. Det är anmärkningsvärt att nästan 50 procent av dem som använt intervjun uppger att de använder den på 81-100 procent av klienterna samtidigt som de endast gjort ett fåtal intervjuer. Förklaringen kan vara att de inte enbart arbetar med klienter med missbruksproblem och därför har få tillfällen att använda ASI-intervjun. En annan anledning kan vara att man är i början av ASI-användningen och att man inte hunnit göra fler intervjuer. Resultatet kan också spegla en ambitionsnivå snarare än en faktisk användning. Resultatet tyder på att det är övergången från sporadisk användning av ASI-intervjun till systematisk användning som är den svåraste fasen i implementeringsprocessen. En annan förklaring till att antalet intervjuer inte ökar över tid kan vara en reaktion mot att ASI inte stämmer med de grundläggande värderingar som finns i socialarbetarkulturen (Garett 2002, Schein 1992). Tidigare erfarenheter från Sverige är att socialarbetare inte gärna använder metoder som man befarar stör mötet med klienten eller förtroendet för socialtjänsten (Ahlberg \& Leissner 1996) även om det visat sig vara en obefogad oro när det gäller ASI-intervjun (Engström \& Armelius 2002). Erfarenheter från Storbritannien är att strukturerade intervjuer och utvärderingar som är baserade på kvantitativa mått möter motstånd hos socialarbetare (Love 1998, Qureshi 1998).

\section{Fas 3. Antalet uppföljningsintervjuer}

Totalt 30 procent eller 62 personer av deltagarna i denna studie har använt uppföljningsintervjun. Hälften av antalet uppföljningsintervjuer har gjorts av tio personer. De återstående 52 personerna som har använt uppföljningsintervjun har i medeltal bara gjort två uppföljningsintervjuer var. Det säger sig självt att deras uppföljningar sannolikt är för få för att det skall vara möjligt att sammanställa intervjuerna på gruppnivå. Resultatet visar sålunda att det är ytterst få som har nått till Fas 3 där interventionen systematiskt följs upp och dokumenteras med en ASI-intervju.

\section{Fas 4. Utvärdering}

Med utvärdering avser vi sammanställning av data på gruppnivå till skillnad 
mot uppföljning som är att följa upp en enskild klient. Uppföljningen kan göras fortlöpande som en källa för individuellt lärande och som feedback till klienten. Utvärdering däremot görs bara vid vissa tidpunkter till exempel i slutet av varje år eller vid andra tidpunkter då det är viktigt med information på gruppnivå. Avser man att följa utvecklingen i en verksamhet måste utvärderingen göras med jämna mellanrum. För att kunna genomföra en utvärdering krävs speciella kunskaper i utvärderingsmetodik och en plan för hur datainsamlingen skall gå till. Utan en plan för hur informationen skall samlas in finns det en risk att informationen blir utan värde. Några viktiga förutsättningar för att kunna göra en regelrätt utvärdering är att ASI-intervjun används systematiskt på alla klienter innan någon behandling eller annan insats påbörjas och att alla klienter sedan följs upp med hjälp av uppföljningsintervjun. Eventuellt bortfall måste dokumenteras för att kunna bedöma om data är representativa för hela klientgruppen. För att det överhuvudtaget skall bli möjligt att skilja ut vad som är en behandlingseffekt så måste alla pågående insatser som kan påverka klienten dokumenteras. I praktiken går det inte att intervjua och följa upp alla klienter utan man måste acceptera ett visst bortfall. Men det är nödvändigt att uppnå en viss kritisk massa av ASI-intervjuer för att det skall vara mödan värt att sammanställa data på gruppnivå. Det är ledningens uppgift att planera utvärderingen, sammanställa och bearbeta dokumentationen på gruppnivå samt att återföra den till användarna.

\section{Ny uppföljande studie}

Denna studie omfattar de första fem åren av implementering av ASI-intervjun. Under den tiden har utbildningen förändrats både till sitt innehåll och till sin omfattning samtidigt som uppföljning och utvärdering har fått en ökad aktualitet. De som utbildades tidigare kan därför ha haft andra förutsättningar att använda ASI-intervjun än de som utbildades senare. Kriminalvården började med sina utbildningar under 1999 medan socialtjänsten och de som arbetar med behandling startade med sina utbildningar redan 1996. Det är troligt att de skillnader som vi funnit mellan kriminalvården och socialtjänsten beror på att verksamheterna kommit olika långt i implementeringsprocessen (Krantz, Schlyter \& Sallmén 2000). Bortfallet är jämförelsevis stort i socialtjänstgruppen vilket kan innebära att resultaten i vissa avseenden är överskattade. Det är rimligt att anta att de som inte svarat på enkäten är sådana som inte använt ASIintervjun.

En ny uppföljande studie av alla som utbildats på ASI-intervjun skulle kunna belysa om de skillnader vi funnit beror på att verksamheterna inte är i fas med varandra. En annan intressant fråga i en uppföljande studie gäller om organisationen har gjort utvärderingar baserade på ASI-data och om sådan information får någon betydelse för den fortsatta utvecklingen av verksamheten. I vår modell förespråkar vi att ASI-intervjun kan vara till nytta både $i$ det enskilda klientarbetet och på organisationsnivå. Resultaten i vår studie visar att den har använts i det direkta klientarbetet och därmed bidragit till ett individuellt

Engström \& Armelius: Implementering av en strukturerad intervju (ASI)... 
lärande. Däremot återstår att besvara, om och i så fall hur, sammanställningar på gruppnivå kan bidra till ett organisatoriskt lärande. Det finns nu också ett dataprogram baserat på ASI-intervjun som underlättar bearbetning och sammanställning av data både på individnivå och på gruppnivå. Dataprogrammets betydelse för implementering av ASI-intervju är en annan intressant fråga för en uppföljande studie.

\section{Sammanfattning}

Resultatet visar att ASI-intervjun kan användas både i socialtjänsten, kriminalvården och i olika behandlingsverksamheter. ASI-intervjun är sålunda en sektorsövergripande dokumentationsmetod som skulle kunna bidra till en ökad grad av samverkan mellan olika verksamheter (Danermark \& Kullberg 1999). Sammanfattningsvis visar vår studie att ASI-intervjun har fått flera intressanta användningsområden i det direkta klientarbetet vilket sannolikt underlättar en fortsatt implementering. Däremot saknas indikationer på att användningen varit planmässig och organiserad trots att chefer och arbetsledare var den vanligaste initiativtagaren till ASI-utbildningarna. För att komma vidare i implementeringen av ASI-intervjun behöver chefer och arbetsledare utbildning hur ASI-intervjun skall implementeras i verksamheten och vad som krävs för att kunna använda intervjun för sammanställningar på gruppnivå.

Först när ASI-intervjun används systematiskt och planerat blir det möjligt att också använda ASI-intervjun till det som den från början var avsedd för, det vill säga att utvärdera resultatet av olika insatser. Systematiska uppföljningar och utvärderingar är onekligen ett djärvt mål men en förutsättning för kunskapsbaserad socialtjänst och en verksamhet vars insatser skall baseras på evidens (SoS 2001). Erfarenheterna från implementeringsforskningen visar dock att det tar lång tid att förändra komplexa organisationer och särskilt när förändringen utmanar den gällande kulturen (Schein 1992).

\section{Referenser}

Ahlberg K. \& Leissner T. (1997) Dokumentation inom missbrukarvården: en processtudie av DOK systemet $i$ Göteborg. Institutionen för socialt arbete Göteborgs Universitet.

Andréasson S, Hjalmarsson K, \& Rehnman C. (2000) "Implementation and dissemination of methods for prevention of alcohol problems in primary health care: A feasibility study". Alcohol and Alcoholism, Vol. 35, No. 5, 525-530.

Andréasson S, Lindström U, Armelius B- $\AA$, Larsson $\mathrm{H}$, Berglund M, Rydberg U, Zingmark D. \&
Tengvald K. (1996) »ASI ett sätt att intervjua klienter i missbrukarvården». Socialstyrelsen, CUS-skrift 1996:1.

Andrén A, Bergman H, Laurell H, \& Schyter F. (2001) „Psykosocial kartläggning av rattfyllerister inom KAPUBRA-projektet». Läkartidningen $\mathrm{nr}$. 32-33, vol. 98, 3426-3432.

Bergmark A. \& Oskarsson L. (1996) „Basdokumentation för socialtjänstens missbrukarvård«. I Berglund, Andréasson, Bergmark, Oscarsson, Tengvald \& Öjehagen (red.) Dokumentation 
inom missbrukarvården. Behandlingsarbetet, Metodutveckling, Utvärdering. Centrum för socialt arbete, Liber. Stockholm.

Bergström, T. (2002) Organisationskultur och kommunal förnyelse. Malmö: Liber förlag.

Björkemarken, M. (1995) Implementeringsanalys som komplement vid utvärdering - en fråga om perspektiv och förklaring. Akademisk avhandling vid Institutionen för Sociologi, Göteborgs Universitet nr 56.

Danermark B. \& Kullberg C. (1999) Samverkan Välfärdsstatens nya arbetsform. Lund: Studentlitteratur.

Department of Health. (1999) Frameworks for the Assessment of Children in Need and their Families. Consultation Draft. London: HMSO.

Engström C. \& Armelius B. A. (2002) "Klienters Acceptans av Strukturerade Intervjuer i Socialtjänsten«. Nordisk Socialt Arbete, Nr. 4, 22.

Friedman, R. M. (2003) "A Conceptual Framework for Developing and Implementing Effective Policy in Children's Mental Health". Journal of Emotional and Behavioural Disorders, Vol. 11.11-18.

Garett, P. M. (2002) »Yes Minister: Reviewing the 'Looking After Children' Experience and Identifying the Messages for Social Work Research". British Journal of Social Work, 32, 831-846.

Gomel M. K, Wutzke S. E, Hardcastle D. M, Lapsley H. \& Reznik R. B. (1998) "Cost-effectiveness of strategies to market and train primary health care physicians in brief interventions techniques for hazardous alcohol use». Social Science Medicine, 47. 203-311.

Grissom G. R. \& Bragg A. (1991) "Addiction Severity Index: Experience in the Field". The International Journal of the Addictions, 26(1), 55-64.

Holland, S. (1999) „Discourses of decision making in child protection: conducting comprehensive assessment in Britain". International Journal of Social Welfare, 8, 277-287

Jenner H. \& Segraeus V. (1996) Att utveckla missbrukarvairden genom dokumentation. Rapport 1996:6, Statens Institutionsstyrelse.

Krantz L, Schlyter F. \& Sallmén B. (2000). Insatser efter behov. ASI/MAPS. Erfarenheter av en försöksverksamhet med förslag till en fortsatt utveckling. Kriminalvårdsstyrelsen, Norrköping.

Lesche, C. (1971) „Om Psykoanalysens Vetenskapsteori». Häften för kritiska studier, 1971:5, s. 7-25.

Leonhard C, Mulvey K, Gastfriend D. R. \& Shwartz M. (2000) "The Addiction Severity Index. A field study of internal consistency and validity". Journal of Substance Abuse Treatment, 18, 129-135.

Lipsky, M. (1980) Street-Level Bureaucracy. Dilemmas of the Individual in Public Services. Russell Sage Foundation.

Love, A. J. (1998) „Internal evaluation: Integrating evaluation and social work practice». Scandinavian Journal of Social Welfare. No. 7, 145-141.

Lundqvist, L. (1987) Implementation Steering. An Actor-Structure Approach. Lund: Studentlitteratur.

McLellan A. T, Luborski L, O’Brien C. P. \& Woody G. (1980) »An Improved Diagnostic Evaluation Instrument for Substance Abuse Patients: The addiction severity index". The Journal of Nervous and Mental Disease, 168: 26-33.

McLellan T. M, Kushner H, Metzger D, Peters R, Smith I, Grissom G, Pettinati H. \& Argeriou M. (1992) »The Fifth Edition of the Addiction Severity Index", Journal of Substance Abuse Treatment, Vol. 9, 199-213.

Qureshi, H. (1998) „Internal and External Evaluation of Social Work". Scandinavian Journal of Social Welfare, No. 7, 137-144.

Sannerstedt, A. (2001) "Implementering - Hur politiska beslut genomförs i praktiken«. I (red) Rothstein, B. Politik som organisation. Förvaltningspolitikens grundproblem. Angered: SNS förlag.

Schein, E. H. (1992) Organization Culture and Leadership, second edition John Wiley \& Sons.

SBU-rapport (2001) Behandling av alkohol- och narkotikaproblem. Volym I och II. SBU, Stockholm. (Nätversion).

SoS 2002:1 Dartingtonprojektet. En försöksverksamhet för att stärka och utveckla familjevården. Stockholm: Socialstyrelsen.

SoS-rapport (2001) Nationellt stöd för kunskaps-

Engström \& Armelius: Implementering av en strukturerad intervju (ASI)... 
utveckling inom socialtjänsten. Rapport $\mathrm{nr}$. 2001:12, Socialstyrelsen. Stockholm.

Webb, S. (2001) "Some Considerations on the Validity of Evidence-based Practice in Social Work". British Journal of Social Work, 31, 57-59.
Wertz J. S, Cleaveland B. L. \& Stephens R. S. (1995) "Problem in the Application of the Addiction Severity Index (ASI) in Rural Substance Abuse Services». Journal of Substance Abuse, 7(2), 175-188.

\section{Summary}

\section{Implementation of a structured interview (ASI) within substance abuse care and the treatment of offenders}

This article presents results from a national survey of those who were trained in the use of the Addiction Severity Index (ASI) in Sweden between 1996 and the first half of 2000. The ASI is a structured evaluation and client assessment method, in the form of an interview, which has become widely distributed in Sweden and internationally (McLellan et al. 1992). ASI training started in Sweden in 1996, on a modest scale initially but later increasing. Up to and including the first months of 2000, approximately 1,000 persons from social services, the prison and probation service and substance abuse care had been trained in conducting the interview.

The aim of the study was to investigate how and to what extent the ASI has been used, as well as what could have facilitated its continued use. The response frequency was $65 \%$, and $70 \%$ of the respondents were female. Of those who returned a completed questionnaire, $60 \%$ had used the ASI in their work, primarily for providing basic information in reports and for assessments of clients' care requirements. The ASI had only been used to a limited extent for follow-up and evaluation. The results further show that the mean number of interviews per respondent is less than ten and that only a few use the ASI systematically. A model for implementing the ASI in four phases is described. 